\title{
Особенности роста наноструктур для терагерцовых квантово-каскадных лазеров и их физические свойства
}

\author{
(C) Г.Э. Цырлин ${ }^{1,2,3,4}$, Р.Р. Резник ${ }^{4}$, А.Е. Жуков ${ }^{1}$, Р.А. Хабибуллин ${ }^{5}$, К.В. Маремьянин ${ }^{6,7}$, \\ В.И. Гавриленко ${ }^{6,7}$, С.В. Морозов 6,7 \\ ${ }^{1}$ Санкт-Петербургский Академический университет им Ж.И. Алфёрова Российской академии наук, \\ 194021 Санкт-Петербург, Россия \\ ${ }^{2}$ Санкт-Петербургский государственный электротехнический университет „ЛЭТИ“, \\ 197376 Санкт-Петербург, Россия \\ ${ }^{3}$ Санкт-Петербургский научный центр Российской академии наук, \\ 199034 Санкт-Петербург, Россия \\ ${ }^{4}$ Университет ИТМО, \\ 197101 Санкт-Петербург, Россия \\ ${ }^{5}$ Институт сверхвысокочастотной полупроводниковой электроники Российской академии наук, \\ 117105 Москва, Россия \\ ${ }^{6}$ Институт фризики микроструктур РАН Российской академии наук - \\ филиал ФИЦ Институт прикладной фризики Российской академии наук, \\ 603950 Нижний Новгород, Россия \\ ${ }^{7}$ Нижегородский государственный университет им. Н.И. Лобачевского, \\ 603950 Нижний Новгород, Россия \\ E-mail: cirlin@beam.ioffe.ru
}

Поступила в Редакцию 15 апреля 2020 г.

В окончательной редакции 21 апреля 2020 г.

Принята к публикации 21 апреля 2020 г.

Приведены данные по синтезу и характеризации структур для квантово-каскадного лазера терагерцового диапазона в системе материалов $\mathrm{AlGaAs} / \mathrm{GaAs}$ на подложках $\mathrm{GaAs}$ с помощью метода молекулярно-пучковой эпитаксии. Рассматриваются особенности, необходимые для реализации подобных структур. Показано, что для данной геометрии наблюдается практически одномодовая генерация на частоте $\sim 3$ ТГц вплоть до температуры $\sim 60 \mathrm{~K}$.

Ключевые слова: квантово-каскадный лазер, молекулярно-пучковая эпитаксия, терагерцовое излучение, полупроводниковые наноструктуры.

DOI: $10.21883 /$ FTP.2020.09.49829.21

\section{1. Введение}

Источники терагерцового (ТГц) диапазона частот интересны с точки зрения применений как гражданского, так и специального назначений, включая определение следовых количеств различных веществ, создание систем формирования изображений объектов, скрытых для обычных оптических систем, широкополосные системы связи и т.д. Одной из основных проблем является отсутствие компактных достаточно мощных монохроматических источников излучения этого спектрального диапазона. Наиболее перспективным кандидатом для реализации ТГц-систем различного назначения в настоящее время считается квантово-каскадный лазер (ККЛ) [1,2]. Несмотря на очевидную научную и практическую значимость ККЛ, в нашей стране эта технология начала развиваться лишь несколько лет назад. Поэтому одной из целей работы было исследование возможности МПЭ синтеза качественных многопериодных многослойных гетероструктур, предназначенных для создания ККЛ ТГц частотного диапазона, а также исследование их физических свойств. Ранее нами были исследованы по- добные структуры с помощью метода фотолюминесценции, а также их вольт-амперные и спектральные характеристики [3-5]. Было показано, что для оценки положения уровней энергии в таких сложных структурах могут быть использованы различные оптические методики экспресс-диагностики, работающие в ближнем ИК диапазоне, и был реализован импульсный режим работы ККЛ при температуре жидкого гелия. В данной работе сообщается об особенностях синтеза, исследовании физических свойств многослойных структур в системе $\mathrm{AlGaAs} / \mathrm{GaAs}$ и о создании полностью отечественного одномодового квантово-каскадного лазера для частотного диапазона 2.9 ТГц, работающего при температуре до $60 \mathrm{~K}$.

\section{2. Эксперимент}

Эпитаксиальные структуры, предназначенные для ККЛ лазеров, были синтезированы методом молекулярно-пучковой эпитаксии в установке МПЭ Riber 21 с использованием твердотельного источника мышьяка. Рост осуществлялся на полуизолирующих подложках 
$\operatorname{GaAs}(100)$ в мышьяк-стабилизированных условиях. Особое внимание уделялось точности установки скоростей роста и поддержанию их стабильности во время формирования активной области. Калибровка скоростей роста проводилась неоднократно для достижения большой точности на отдельном образце непосредственно перед ростом ККЛ структур. В частности, предварительная калибровка скоростей роста проводилась в течение 40 ч, составляющих типичное время роста структуры ККЛ, с целью обеспечения неизменности потоков за этот период. Скорости роста по GaAs и AlAs были установлены равными 0.85 и 0.15 монослоя в секунду $(\mathrm{MC} / \mathrm{c})$ соответственно. Для уменьшения толщины переходных слоев использовались специальные высокоскоростные заслонки для уменьшения „перевсплесков“ при синтезе слоев. В нашем случае измеренная с помощью специального стенда скорость срабатывания заслонок алюминиевого и галлиевого источников не превышала $0.18 \mathrm{c}$.

Лазерные структуры были выращены по следующей последовательности. Во-первых, выращивался буферный слой $\mathrm{GaAs}$ для выравнивания поверхности подложки после сгона окисного слоя. На буферном слое $\mathrm{GaAs}$ был осажден стоп-слой $\mathrm{Al}_{0.8} \mathrm{Ga}_{0.2} \mathrm{As}$ толщиной 200 нм. Активная область содержала 228 периодов, каждый из которых имел следующую структуру: 43/75.6/24.6/69.3/41/136, где толщина слоев $\mathrm{A} 10.15 \mathrm{Ga} 0.85 \mathrm{As} / \mathrm{GaAs}$ обозначена в ангстремах. Каждый каскад содержит двойную квантовую яму GaAs/AlGaAs, между уровнями которой происходит лазерный переход, и более широкую квантовую яму, служащую инжектором/экстрактором электронов. Снизу и сверху активная область была ограничена контактными слоями $\mathrm{GaAs}: \mathrm{Si}$ $\left(5 \cdot 10^{18} \mathrm{~cm}^{-3}\right)$ толщиной 75 нм. Средняя часть слоев инжектора/экстрактора также имела легирование $n$-типа с концентрацией около $5 \cdot 10^{16} \mathrm{~cm}^{-3}$.

Структурные свойства эпитаксиальных образцов исследовались с помощью рентгеновской дифракции высокого разрешения. Использовался дифрактометр D8 DISCOVER Bruker AXS $(\lambda=0.15406$ нм) с полушириной первичного пучка $<12^{\prime \prime}$ в режиме $\Omega-2 \Theta$ сканирования. Кроме того, для исследования шероховатости поверхности использовалась атомно-силовая микроскопия (АСМ), а для визуализации различных слоев, составляющих гетероструктуру, - метод просвечивающей электронной микроскопии (ПЭМ) и вторичной ионной масс-спектрометрии (ВИМС).

Для создания ККЛ в данной работе была использована схема волновода типа металл-металл, в которой активная область заключалась между двумя металлическими слоями. Такой волновод обеспечивает более сильную локализацию поля и меньшие потери по сравнению с плазмонным волноводом [3], хотя такой подход значительно усложняет постростовую обработку структур. Для создания как волноводного ограничения, так и омических контактов была использована металлизация Ti/Au
(10/500 нм). Выращенную структуру помещали на проводящую подложку-носитель $n^{+}$-GaAs, на поверхность которой были нанесены такие же металлические слои, и сращивали методом термокомпрессионного соединения с использованием пары $\mathrm{Au}-\mathrm{Au}$. Затем производилось последовательное стравливание исходной подложки до стоп-слоя, а затем и самого стоп-слоя, после чего сверху наносилась аналогичная последовательность металлических слоев Ti/Au. В результате структура толщиной $\sim 10$ мкм оказывалась ограниченной двумя металлическими слоями. Далее с использованием электроннолучевой литографии и сухого травления формировались полоски шириной 100 мкм Подробное описание процессов формирования волновода представлено в работе [4]. После утончения подложки-носителя до толщины $\sim 100$ мкм выкалывались лазерные чипы длиной $\sim 1.5$ мм. Какие-либо покрытия или линзы на сколотые грани не наносились. Чипы монтировались на медный теплопровод, являющийся нижним контактом к структуpe. К верхнему контакту напаивалась золотая проволока.

Для подтверждения факта возникновения лазерной генерации в исследуемых ККЛ были измерены спектры излучения. Измерения выполнялись с помощью фурьеспектрометра BRUKER Vertex 80v при различных температурах.

\section{3. Результаты}

Как уже упоминалось, при синтезе методом МПЭ гетероструктур, предназначенных для генерации излучения ТГц-диапазона, толщина которых составляет $\sim 10$ мкм, может происходить изменение скорости роста GaAs вследствие истощения источников галлия и алюминия в процессе длительного осаждения. По этой же причине может иметь место неравномерность толщин слоев в структуре. Чтобы прояснить, насколько велико влияние точного поддержания скорости осаждения арсенида галлия, нами были синтезированы и исследованы подобные структуры.

На рис. 1 показана типичная кривая качания вблизи симметричного рефлекса (004) GaAs, измеренная на структуре QCL-1. Ширина на половине высоты сателлитных пиков, обусловленных периодическим повторением каскадов ККЛ, составляет 15-19". Отметим, что полная ширина сверхструктурных пиков в модельном спектре с учетом изгиба структуры под действием упругих напряжений составляет $22.4^{\prime \prime}$. Это означает, что в исследуемых структурах можно пренебречь как возможным влиянием неточности поддержания толщины каскада в пределах всей структуры, так и шероховатостью гетероинтерфейсов, подтверждая правильность выбора технологических параметров при синтезе активной области.

Согласно АСМ-измерениям установлено, что средняя шероховатость поверхности составляет $2 \AA$, что соот- 


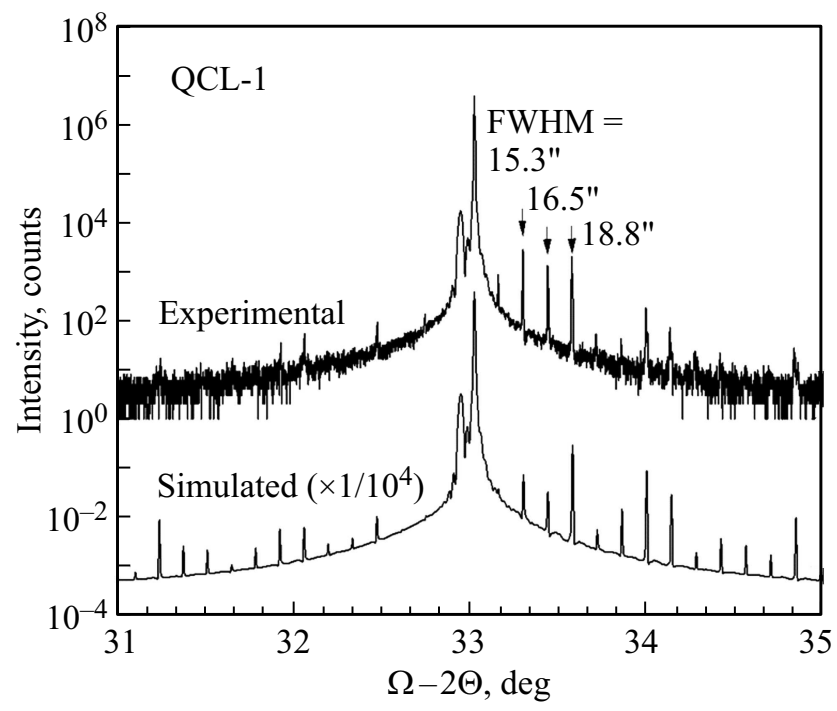

Рис. 1. Рентгеновская кривая качания структуры ККЛ-1 вблизи рефлекса $\mathrm{GaAs}(004)$, а также модельная кривая.

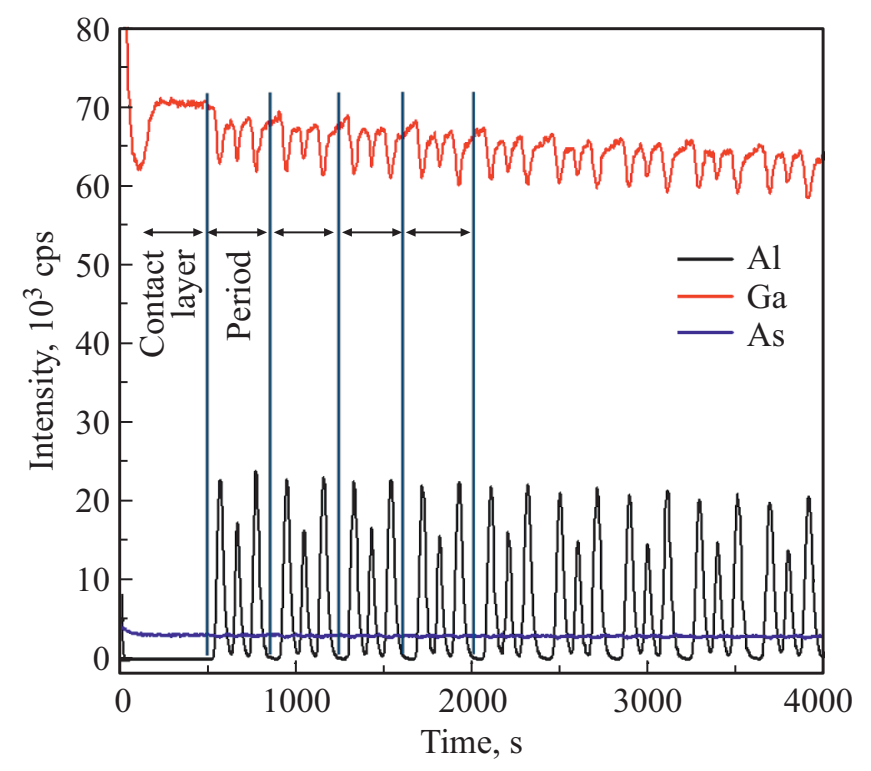

Рис. 2. Типичный ВИМС профиль ККО структуры.

ветствует практически идеальной гладкости выращенной структуры.

Для подтверждения качества выращенных структур было проведено их исследование методом ВИМС. На рис. 2 представлен типичный вид ВИМС характеристик исследованных структур. Из рисунка следует, что наблюдаются четкие повторения периодических пиков с практически аналогичной интенсивностью, что указывает на хорошее качество эпитаксиального роста.

Кроме того, были детально исследованы структурные свойства эпитаксиальных образцов с помощью метода ПЭМ. На рис. 3 приведено изображение ПЭМ верхней части ККЛ структуры, показывающее высокое качество синтезированных образцов, резкую границу раздела между слоями по всей структуре и равномерность толщин различных слоев.

Для подтверждения факта возникновения лазерной генерации в исследуемых ККЛ были измерены спектры излучения при различных температурах. Было обнаружено сужение линии излучения по достижении порога лазерной генерации с последующим превращением спектра излучения в набор узких линий, соответствующих продольным модам лазерного резонатора (рис. 4). Доминирующая мода имеет частоту 2.9 ТГц при $T=10 \mathrm{~K}$. Спектр генерации имеет квазиодночастотный характер, интенсивность побочных мод по отношению к доминирующей лазерной моде подавлена более чем на порядок. Следует отметить, что лазерная генерация наблюдалась до температуры $\sim 60 \mathrm{~K}$.

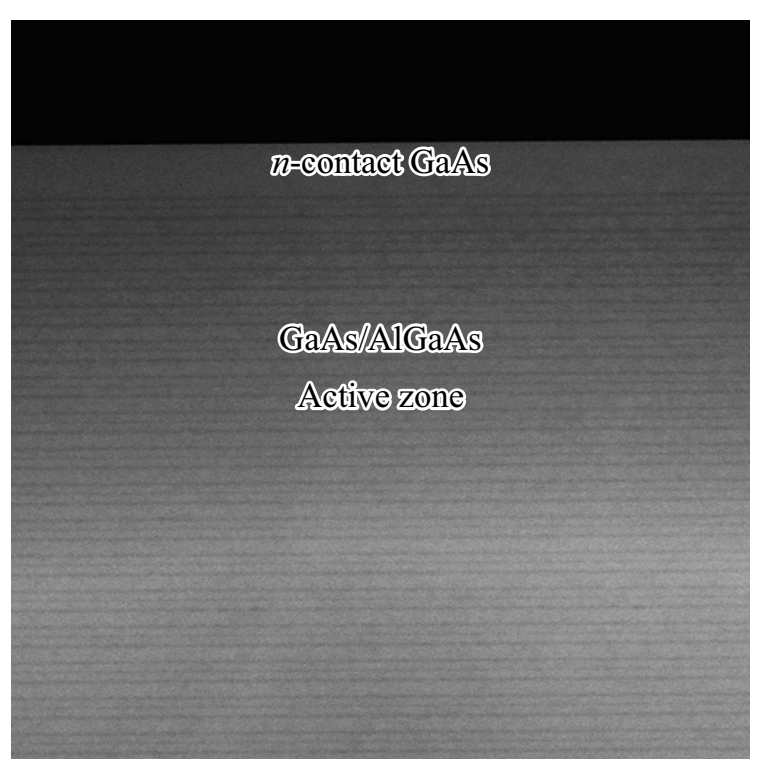

Рис. 3. ПЭМ-изображение верхней части ККЛ структуры.

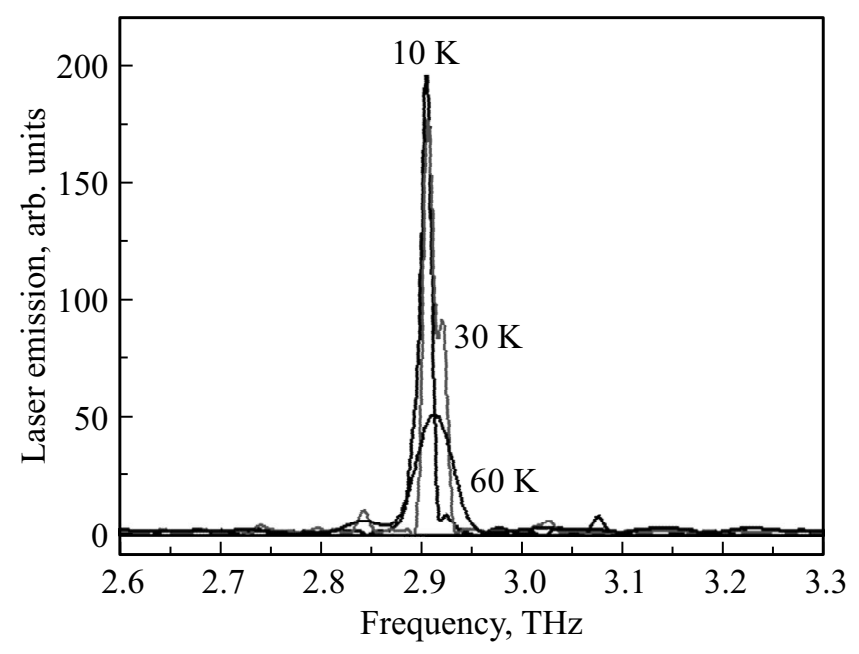

Рис. 4. Спектры излучения квантово-каскадного лазера, измеренные при различных температурах (при 10 и $30 \mathrm{~K}$ разрешение спектрометра $0.3 \mathrm{~cm}^{-1}$, при $\left.60 \mathrm{~K}-1 \mathrm{~cm}^{-1}\right)$. 


\section{4. Заключение}

Таким образом, были успешно выращены структуры для квантово-каскадных лазеров, работающих в терагерцовом диапазоне. Структурные и оптические свойства выращенных структур показывают их высокое качество. Показано, что для данной геометрии наблюдается практически одномодовая генерация на частоте $\sim 3$ ТГц вплоть до температуры $\sim 60 \mathrm{~K}$.

\section{Финансирование работы}

Работа выполнена при частичной поддержке Программы фундаментальных исследований Президиума РАН „Основы высоких технологий и использование особенностей наноструктур в науках о природе“. Измерения лазерных структур проведены при поддержке Российского научного фонда проект № 18-19-00493.

\section{Конфликт интересов}

Авторы заявляют, что у них нет конфликта интересов.

\section{Список литературы}

[1] Р.Ф. Казаринов, Р.А. Сурис. ФТП, 5 (4), 797 (1971).

[2] J. Faist, F. Capasso, D.L. Sivco, C. Sirtori, A.L. Hutchinson, A.Y. Cho. Science, 264, 553 (1994).

[3] А.Е. Жуков, Г.Э. Цырлин, Р.Р. Резник, Ю.Б. Самсоненко, А.И. Хребтов, М.А. Калитеевский, К.А. Иванов, Н.В. Крыжановская, М.В. Максимов, Ж.И. Алфёров. ФТП, 50 (5), 674 (2016).

[4] Р.А. Хабибуллин, Н.В. Щаврук, А.Ю. Павлов, Д.С. Пономарев, К.Н. Томош, Р.Р. Галиев, П.П. Мальцев, А.Е. Жуков, Г.Э. Цырлин, Ф.И. Зубов, Ж.И. Алфёров. ФТП, 50 (10), 1395 (2016).

[5] А.В. Иконников, К.В. Маремьянин, С.В. Морозов, В.И. Гавриленко, А.Ю. Павлов, Н.В. Щаврук, Р.А. Хабибуллин, Р.Р. Резник, Г.Э. Цырлин, Ф.И. Зубов, А.Е. Жуков, Ж.И. Алфёров. Письма ЖТФ, 43 (7), 86 (2017).

Редактор А.Н. Смирнов

\section{Features of the growth of nanostructures for terahertz quantum cascade lasers and their physical properties}

\author{
G.E. Cirlin 1,2,3,4, R.R. Reznik ${ }^{4}$, A.E. Zhukov', \\ R.A. Khabibullin ${ }^{5}$, K.V. Maremyanin ${ }^{6,7}$, \\ V.I. Gavrilenko ${ }^{6,7}$, S.V. Morozov ${ }^{6,7}$ \\ ${ }^{1}$ St. Petersburg Academic University \\ of the Russian Academy of Sciences, \\ 194021 St. Petersburg, Russia \\ 2 St. Petersburg Electrotechnical University "LETI", \\ 197376 St. Petersburg, Russia \\ ${ }^{3}$ St. Petersburg Scientific Center \\ of the Russian Academy of Sciences, \\ 199034 St. Petersburg, Russia \\ ${ }^{4}$ ITMO University, \\ 197101 St. Petersburg, Russia \\ ${ }^{5}$ Institute of Ultrahigh Frequency \\ Semiconductor Electronics \\ of the Russian Academy of Sciences, \\ 117105 Moscow, Russia \\ ${ }^{6}$ Institute for Physics of Microstructures, \\ Russian Academy of Sciences, \\ 603950 Nizhny Novgorod, Russia \\ ${ }^{7}$ Lobachevsky State University, \\ 603950 Nizhny Novgorod, Russia
}

\begin{abstract}
The data on the synthesis and characterization of structures for a quantum cascade terahertz laser in an $\mathrm{AlGaAs} / \mathrm{GaAs}$ material system on GaAs substrates using the molecular beam epitaxy method are presented. The features necessary for the implementation of such structures are considered. It was shown that for this geometry almost single-mode lasing is observed at a frequency of $\sim 3 \mathrm{THz}$ up to a temperature of $\sim 60 \mathrm{~K}$.
\end{abstract}

